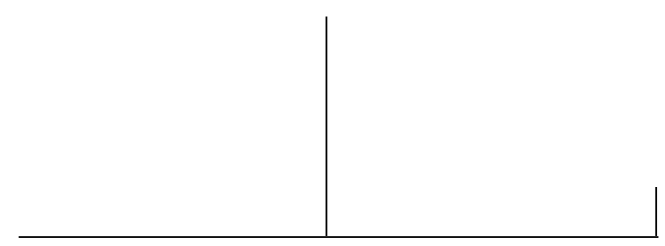

Rev. Latinoam. Psicopat. Fund., São Paulo, v. 12, n. 2, p. 393-410, junho 2009

\title{
Os caminhos da loucura na Corte Imperial: um embate historiográfico acerca do funcionamento do Hospício Pedro II de 1850 a 1889*
}

\begin{abstract}
O tema da alienação mental ganhou relevo na segunda metade do século XIX no Rio de Janeiro, com a inauguração do Hospício Pedro II, um espaço hospitalar especial para o recolhimento e tratamento destes doentes. No entanto, como já demonstrou a bibliografia referente ao tema, a trajetória desta instituição e sua relação com a ideia de cura elou exclusão ainda suscita divergências. Sendo assim, neste artigo será desenvolvida uma discussão sobre os principais aspectos desta temática, apresentando o resultado de uma análise de fontes inéditas, reveladoras de novos aspectos do cotidiano desta instituição.
\end{abstract}

Palavras-chave: História da medicina, alienação mental, Hospício Pedro II, Brasil-Império

* Versão modificada de comunicação apresentada na Mesa-redonda "A conformação histórica do campo da psiquiatria no Brasil", durante o III Congresso Internacional e IX Congresso Brasileiro de Psicopatologia Fundamental (Niterói, RJ, setembro de 2008). Trabalho resultante de pesquisa de doutoramento, que se encontra em andamento, no Programa de Pós-Graduação da Casa de Oswaldo Cruz/COC, orientada pelo Prof. Dr. Flavio Coelho Edler e financiada pela Fiocruz. 
Apresentação

No início da década de 1830 , discussões envolvendo a situação dos alienados mentais que vagavam pelas ruas e o tratamento a que eram submetidos aqueles que se encontravam reclusos nas enfermarias da Santa Casa de Misericórdia ganharam relevo na Corte Imperial, mobilizando membros da Sociedade de Medicina do Rio de Janeiro $^{1}$ e da Faculdade de Medicina do Rio de Janeiro. ${ }^{2}$ Os maustratos, a falta de um tratamento físico e moral condizente, de um médico especialista, de enfermeiros competentes e, sobretudo, de condições higiênicas adequadas ao tratamento de doentes constavam nas denúncias formuladas nesta década pelos membros da Comissão de Salubridade Geral da Sociedade de Medicina do Rio de Janeiro, ${ }^{3}$ que a partir destas constatações passavam a reivindicar a criação de um estabelecimento dedicado especialmente ao tratamento de alienados (Machado et al., 1978; Engel, 2001; Teixeira, 1998).

Com o coroamento do Imperador Pedro II em 1841, o projeto de construção de um asilo para o tratamento de alienados, apresentado pelo então provedor da Santa Casa de Misericórdia José Clemente Pereira, foi aprovado por decreto de 18 de julho de 1841 e a construção do "Palácio dos Loucos", na Praia da Saudade, se principiou com uma enorme lista de subscritores, dentre os quais estava o próprio Imperador. Para a edificação do suntuoso prédio também foram utilizados recursos advindos de donativos, comutações de penas, loterias, esmolas e rendimentos da chácara. ${ }^{4}$

1. Até 1835 essa associação médica era denominada Sociedade de Medicina do Rio de Janeiro, mudando para Academia Imperial de Medicina nesse ano.

2. Dentre estes constavam os médicos José Martins da Cruz Jobim, Joaquim José da Silva, Christóvão José dos Santos, José Francisco Xavier Sigaud, Luiz Vicente De-Simoni e Antonio L. da Silva Peixoto. Este último defendera em 1837, na Faculdade de Medicina do Rio de Janeiro, a primeira tese sobre alienação mental desta instituição.

3. Participaram desta Comissão os médicos: José Martins da Cruz Jobim, Joaquim José da Silva e Christóvão José dos Santos.

4. Maço IS 33 (1840-1849), Ministério do Império - Série Saúde, Arquivo Nacional, AN. 
HISTÓRIA DA

PSIQUIATRIA

Enquanto isso, foi estabelecido no terreno onde seria erguido o hospício um asilo provisório que desde aquela data passava a receber os alienados que estavam nas enfermarias do Hospital Geral da Santa Casa de Misericórdia.

Em dezembro de 1852, o Hospício Pedro II começou a receber os loucos oficialmente, representando a primeira instituição voltada especialmente para o tratamento de alienados no Brasil (Sant'Anna, 2002). Segundo o "Projeto dos Estatutos do Hospício Pedro II", o funcionamento do hospício seria dividido em econômico (administradores), sanitário (facultativos auxiliados pelas irmãs de caridade) e religioso (capelães).

Quanto à admissão de alienados, ficava estabelecido que os mesmos poderiam ser recebidos em quatro categorias, indigentes (não pagantes), pensionistas de $1^{\text {a }}$ classe, $2^{\text {a }}$ classe ou $3^{\text {a }}$ classe, pelas quais seriam pagas cotas diárias de acordo com a classe.

Em sua inauguração o hospício estava apto a receber 150 pacientes, mas este número cresceria com o fim das obras em 1854, passando a sua capacidade para 300 alienados (150 homens e 150 mulheres). Esta cifra só seria estendida na década de 70 com novas obras de ampliação do edifício, que aumentariam a capacidade de recebimento de pacientes homens para cerca de 240 alienados. ${ }^{5}$

Todos os autores que já trataram do tema ressaltaram a importância da constituição do Hospício Pedro II, atentando para a sua relevância no cenário nacional, como a primeira instituição deste cunho (Machado, 1978; Costa, 1989; Teixeira, 1998; Costa, 2000; Resende, 2000; Engel, 2001; Sant'Anna, 2002), pois apesar da abertura de outros hospícios sucessivamente em São Paulo (1852), Pernambuco (1864), Pará (1873), Bahia (1874), Rio Grande do Sul (1884), Ceará (1886) e Alagoas (1888) (Moreira, 1903; Oda \& Dalgalarrondo, 2005), o hospício da capital ocupou a posição de principal estabelecimento deste cunho durante todo o Segundo Reinado.

No entanto, ainda existem muitas divergências quanto ao papel que este estabelecimento cumprira, assim como ainda são nebulosos muitos aspectos relativos ao seu funcionamento ao largo dos seus 37 anos de existência. ${ }^{6}$ Questões muito limitadas, certamente, pela pouca diversidade de fontes a que tiveram acesso os diversos autores.

5. Não apareceu claramente nos documentos a que tive acesso a quantidade exata de novos leitos. Este número foi deduzido de acordo com o aumento na admissão de homens após o término da dita obra.

6. Com a República, o Hospício Pedro II passou a ser denominado Hospício Nacional de Alienados - esta demarcação foi utilizada para fins de recorte cronológico para a pesquisa.

Rev. Latinoam. Psicopat. Fund., São Paulo, v. 12, n. 2, p. 393-410, junho 2009 


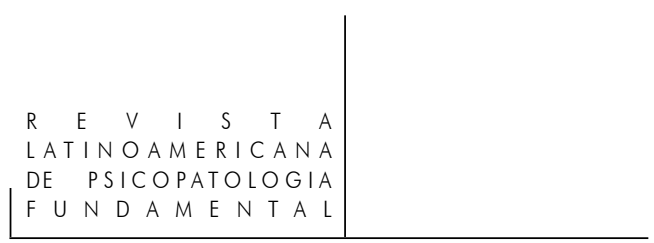

Sendo assim, me dedicarei neste trabalho à revisão de alguns aspectos ressaltados nos principais trabalhos historiográficos, com base em novas fontes documentais, ${ }^{7}$ visando compreender aspectos que se referem tanto ao cotidiano do principal asilo de alienados do Império, como no que tange às possíveis trajetórias traçadas por aqueles "infelizes", ${ }^{8}$ afetados em suas faculdades intelectuais.

Quais pacientes eram admitidos no Hospício Pedro II? Qual a sua importância no cenário nacional? O que mudou no município da Corte com a sua construção? Fora este constituído para tirar de circulação loucos de qualquer espécie? Qual era o seu objetivo fundamental? Que outras instituições ainda continuaram a receber alienados mentais? Estes são alguns dos principais pontos ainda não respondidos satisfatoriamente pela historiografia e aos quais pretendemos nos ater neste artigo.

\section{Os pacientes do Hospício Pedro II}

Em dezembro de 1852 foram abertas as portas do Hospício Pedro II reordenando, em certa medida, o leque de espaços possíveis a serem ocupados pelos indivíduos que apresentavam problemas mentais.

Dentre os seus primeiros ocupantes, José Clemente Pereira, provedor da Santa Casa, relacionara 74 homens e 66 mulheres, dos quais 126 eram classificados como tranquilos, 10 como agitados e 4 como imundos. Destes, 63 eram brasileiros, 57 estrangeiros e 20 tinham a nacionalidade ignorada. Quanto à procedência, 113 advinham do Município da Corte, 20 da Província do Rio de Janeiro e 7 de outras Províncias do Império: 1 de Minas Gerais, 1 de Santa Catarina, 4 do Rio Grande e 1 do Sergipe. ${ }^{9}$

7. Um grande levantamento de fontes realizado no Arquivo Nacional nos possibilitou o acesso a um extenso número de documentos ainda não analisados pela historiografia que se dedicou a este tema. Este artigo apresenta uma pequena parte dos resultados obtidos com esta pesquisa que tem como objetivo a composição de uma tese de doutorado a ser defendida no início de 2010, no Programa de Pós-Graduação da Casa de Oswaldo Cruz.

8. Expressão comumente utilizada pelos médicos do hospício e mesmo pelas autoridades públicas nas fontes a que tive acesso.

9. Pereira, José Clemente. Alienados que passaram do antigo hospital e das enfermarias provisórias para o Hospício de Pedro Segundo nos dias 8 e 9 de dezembro de 1852. In: Maço IS 3 4, Ministério do Império - Série Saúde (1850-1853), Arquivo Nacional, AN. 
HISTÓRIA DA

PSIQUIATRIA

Se neste primeiro momento a grande maioria de seus ocupantes era procedente do Município da Corte, ${ }^{10}$ esta situação mudaria rapidamente. Logo se multiplicariam os pedidos de internamento feitos pelos diversos presidentes de Província e principalmente pelas Santas Casas de todo o Império. ${ }^{11}$

Pela análise dos fundos documentais do Arquivo Nacional, percebemos que após a abertura oficial do Hospício Pedro II, tornou-se recorrente o envio de alienados de diversas Províncias, que eram simplesmente embarcados em vapores com destino ao Porto do Rio de Janeiro. Chegando à Corte, estes eram deixados perambulando pela cidade até que fossem recolhidos pela polícia, quando enfim eram levados ao seu destino, o hospício, no qual eram recebidos na grande maioria das vezes como indigentes.

A fama do novo hospício se espalhara de tal modo que uma carta do provedor José Clemente Pereira ao Ministro do Império, em 1853, pedia que se relatasse ao Imperador a chegada de uma alienada de nome Isabel Dorrego, filha do General Dorrego, de Buenos Aires, que tinha vindo para a Corte, desde abril de 1852 , ficando na cidade à espera da abertura do asilo, somente com o objetivo de ser tratada como pensionista de $1^{\text {a }}$ classe. Ocorrência que era relatada pelo provedor ao Ministro do Império, ressaltando as inconveniências na aceitação de alienados dos países vizinhos sem a ofensa dos estatutos, já que o mesmo definira que o hospício deveria atender aos alienados do Império. ${ }^{12}$

A crescente demanda de vagas para alienados foi, durante os seus 37 anos de existência, ${ }^{13}$ um problema para a administração do hospício, assim como para as autoridades policiais da Corte. Em carta enviada ao provedor da Santa Casa pelo administrador do hospício em 1856, era ressaltada a difícil situação financeira que vinha enfrentando o estabelecimento durante toda a década de 1950 . O que também pode ser verificado em todos os relatórios apresentados pelo hospício até a década de 1970, em que o déficit nas suas contas estava sempre presente e a reclamação de que a receita não era suficiente para a manutenção da administração e tratamento dos doentes indigentes era apontada como um grande problema. ${ }^{14}$

10. As procedências registradas como sendo do Município da Corte certamente faziam referência às autoridades pelos quais eram enviados.

11. Relatório da Santa Casa de Misericórdia de $1^{\circ}$ de julho de 1851 a 30 de junho de 1852 . In: Maço IS 3 4, Ministério do Império - Série Saúde (1850-1853), Arquivo Nacional, AN.

12. Maço IS 3 4, Ministério do Império - Série Saúde (1850-1853), Arquivo Nacional, AN.

13. Os 37 anos de existência se referem ao tempo em que este hospício se chamou Hospício Pedro II, de 1852 até 1889 .

14. Maços IS 3 3, IS 3 4, IS 3 5, IS 36 e IS 3 7, Ministério do Império - Série Saúde, Arquivo Nacional, AN.

Rev. Latinoam. Psicopat. Fund., São Paulo, v. 12, n. 2, p. 393-410, junho 2009 


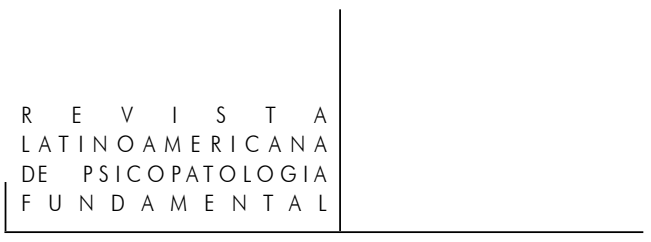

Nesse ano, além de pedir a reforma dos estatutos para possibilitar a remarcação anual do preço das diárias pagas pelos pensionistas, o administrador já ressaltava que os dilemas enfrentados também se relacionavam com a remessa de enfermos, enviados por autoridades policiais, que iam de paralíticos e epiléticos a "bêbados de profissão e até um cego que para lá foi mandado da albergueria da Corte". ${ }^{15}$

No que se refere à população recolhida ao hospício, a historiografia apresenta muitas divergências. Todos os autores, no entanto, convergem no tocante à quantidade de indigentes em seus quadros, tendo em vista a presença maciça de pacientes assim classificados em todas as estatísticas confeccionadas por esse estabelecimento durante o período. No entanto, mesmo atestando a presença majoritária de "pobres", os autores discordam em importantes pontos.

Manoel Olavo Teixeira (1998), ao tomar como fonte somente os dados deixados por Philipe Rey, em L'Hospice Pédro II et les Alienés au Brésil, conclui que o "nababesco hospício de Pedro II nasce com missão de prestar atendimento a brancos e europeus residentes no Império, destinando uma pequena parte de seu funcionamento aos negros e mestiços praticamente não atendendo a escravos" (p.143).

No entanto, ao lermos as fontes abaixo podemos ter uma visão bem distinta deste "nababesco hospício":

\begin{tabular}{|c|c|c|c|c|}
\hline \multicolumn{5}{|c|}{$\begin{array}{c}\text { Tabela } 1 \\
\text { Movimentação de estrangeiros } \\
\text { no período } 9 \text { de dezembro de } 1852 \text { a } 31 \text { de dezembro de } 1856\end{array}$} \\
\hline Nacionalidade & Entraram & Tiveram alta & Faleceram & Permaneceram \\
\hline Portugal & $158(31,9 \%)$ & 79 & 44 & 35 \\
\hline Espanha & $5(1 \%)$ & 4 & 1 & - \\
\hline França & $23(4,6 \%)$ & 17 & 4 & 2 \\
\hline Alemanha & $27(5,4 \%)$ & 13 & 7 & 7 \\
\hline Inglaterra & $12(2,4 \%)$ & 10 & 2 & - \\
\hline Itália & $4(0,8 \%)$ & 2 & - & 2 \\
\hline Prússia & $5(1 \%)$ & 4 & - & 1 \\
\hline Suíça & $3(0,6 \%)$ & 2 & - & 1 \\
\hline Estados Unidos & $4(0,8 \%)$ & 2 & 1 & 1 \\
\hline Chile & $1(0,2 \%)$ & 1 & - & - \\
\hline Buenos Ayres & $1(0,2 \%)$ & 1 & - & - \\
\hline China & $2(0,4 \%)$ & - & 1 & 1 \\
\hline África & $249(50 \%)$ & 152 & 72 & 25 \\
\hline
\end{tabular}

15. Maço IS 3 5, Ministério do Império - Série Saúde, Arquivo Nacional, AN. 
A substancial presença de africanos, nesta estatística dos primeiros quatro anos de existência do hospício, nos oferece um outro panorama da sua população. As conclusões de Teixeira sobre a natureza deste asilo derivaram, certamente, do acesso restrito ao trabalho de Rey, o qual, tendo sido produzido na década de 1970, além de não poder servir de amostra para todo o período, deve ser relativizado. ${ }^{16}$ Tomando como fonte a estatística apresentada de 1852 a 1856 , quanto à condição civil dos pacientes temos a seguinte situação:

Tabela 2

Classificação dos pacientes de acordo com a sua condição civil $(1852-1856)^{17}$

$\begin{array}{ccccc}\text { Condição } & \text { Entraram } & \text { Tiveram alta } & \text { Faleceram } & \text { Permaneceram } \\ \text { Livres } & 961(86,5 \%) & 401(36 \%) & 299(27 \%) & 261(23,5 \%) \\ \text { Escravos } & 149(14,5 \%) & 107(9,6 \%) & 30(2,7 \%) & 12(1 \%)\end{array}$

Fonte: Maço IS 3 5, Ministério do Império - Série Saúde, AN.

Cruzando os dados acima com a tabela referente à nacionalidade dos pacientes internados no hospício nesse mesmo período, que contabilizava a entrada de 249 africanos, podemos perceber que muitos destes estavam classificados como livres. Esta constatação nos indica também para a possibilidade de alguns escravos serem classificados como brasileiros, ou mesmo de muitos não serem declarados como escravos,$^{18}$ o que, efetivamente, aumentaria muito mais a quantidade de negros no hospício, contrariando a afirmação de Teixeira.

Sabemos que a identificação dos alienados era realizada de acordo com a declaração dos seus dados pelos familiares (quando estes eram os requerentes da internação), quando não era fornecida pelas autoridades responsáveis pelo seu

16. Relativização que deve se dar pela exatidão de seus dados, tendo em vista que a partir da década de 80 as estatísticas apresentavam sempre um grande número de alienados sobre os quais não se sabia a nacionalidade.

17. Maço IS 3 5, Ministério do Império - Série Saúde (1854-1857), Arquivo Nacional, AN.

18. No caso de um escravo alienado, o mesmo só poderia ser tratado como indigente se o senhor do escravo comprovasse não poder pagar o seu tratamento, caso contrário seria recebido como pensionista de terceira classe, com cotas diárias definidas pelo Estatuto. Este aspecto do Estatuto do Hospício Pedro II nos aponta para a probabilidade de existirem dentre os pacientes indigentes muitos escravos não declarados. Projeto dos estatutos do Hospício Pedro II. In: Maço IS 3 4, Ministério do Império - Série Saúde (1850-1853), Arquivo Nacional, AN.

Rev. Latinoam. Psicopat. Fund., São Paulo, v. 12, n. 2, p. 393-410, junho 2009 


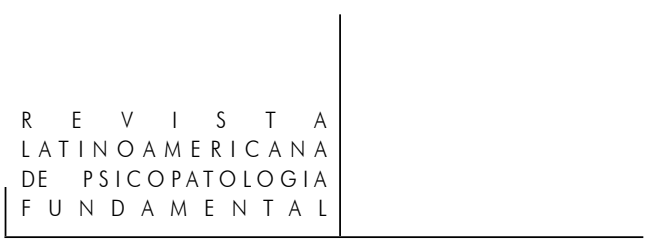

recolhimento, como a polícia. Na segunda situação concluímos, com base na documentação analisada, que eram muito precários os dados daqueles recolhidos nas ruas, e sendo muito numerosas estas ocorrências podemos asseverar que existia uma boa quantidade de indivíduos não identificados dentro do hospício.

Como afirma Magali Engel (2001) em uma nota de rodapé, havia a possibilidade de que, entre indigentes livres ou libertos estivessem incluídos alguns desses escravos, "cuja condição de cativos era, muitas vezes, dificilmente identificável" (p. 223). Podemos conjeturar, no entanto, que a população escrava, ou mesmo negra, presente no hospício na década de 1950 fosse superior àquela presente neste estabelecimento na década de 1970 em diante por questões contextuais como a interrupção do tráfico de escravos e, consequentemente, da drástica diminuição da entrada de africanos no porto do Rio de Janeiro. Ou mesmo podemos corroborar com a perspectiva de Engel quanto ao aumento da venda de escravos para o interior do país, tendo em vista a valorização da mão de obra cativa e a sua concentração em atividades do setor básico (Chalhoub, 1990). ${ }^{19}$

No entanto, mesmo apontando para a possibilidade de diminuição do número de negros e escravos (mesmo aqueles não identificados como tais), seria um equívoco qualificar como uma instituição restrita aos brancos, como nos aponta Teixeira, após termos travado contato com fontes da década de 1950.

\section{O movimento do Hospício Pedro II}

Ao tomarem como fontes as querelas incitadas pelo médico Nuno de Andrade, a partir de $1882,{ }^{20}$ e os trabalhos posteriores de Teixeira Brandão (1886) e Juliano Moreira (1903), todos os pesquisadores que se dedicaram a esta temática chegaram a conclusões distorcidas acerca do funcionamento do hospício. Principalmente no que se refere à compreensão do processo de admissão dos alienados.

19. Sidney Chalhoub também alerta para a grande diminuição do número de escravos na cidade com a supressão do tráfico em 1850 .

20. Em 1882 foram publicados no Jornal do Commercio diversas cartas trocadas entre o médico Nuno de Andrade, responsável pelo serviço médico do hospício na época, e o provedor da Santa Casa de Misericórdia, Visconde de Jaguary. Nestas, o referido médico fazia fortes denúncias ao tratamento dado aos alienados pelos enfermeiros e irmãs de caridade, se opondo ao poder que detinha a Irmã Superiora no controle do Hospício, e, por isto, propondo que o Hospício Pedro II fosse desanexado da Santa Casa.

Rev. Latinoam. Psicopat. Fund., São Paulo, v. 12, n. 2, p. 393-410, junho 2009 
HISTÓRIA DA

PSIQUIATRIA

Partindo desses documentos, Engel (2001) afirma que a admissão dos alienados no hospício era realizada exclusivamente por intermédio do Provedor da Santa Casa, "que por sua vez só podia ordenar matrícula mediante diversos documentos" (p. 233). O que para a autora significava que os olhos dos médicos não decidiam sozinhos pela loucura ou não dos pacientes. Por outro lado, Teixeira ressalta que a proibição de novas internações em 1862, por parte da provedoria, teria feito com que as autoridades públicas encaminhassem os loucos que perturbavam a ordem da cidade para o Asilo de Mendicidade ou para as cadeias públicas, a partir daquele momento.

No entanto, como podemos observar em documentos datados de 1862, apesar das reiteradas reivindicações feitas ao Ministério do Império até aquele ano, o número de remessas irregulares de pacientes para o hospício alcançou o seu ápice. Em carta ao provedor, ${ }^{21} \mathrm{o}$ médico Manoel José Barbosa afirmava que, apesar das novas regras de admissão, as remessas de alienados do Xadrez da polícia da Corte e da Província do Rio de Janeiro continuavam a ser abusivas. Visto que, mesmo depois de se chamar atenção para os problemas causados com o envio de imbecis e idiotas ${ }^{22}$ ao hospício, o mesmo continuou a se fazer, resultando com que o estabelecimento somasse, naquele ano, um total de 215 homens e $185 \mathrm{mu}$ lheres, ou seja, 400 pacientes $!^{23} \mathrm{E}$ em face ao grande número de doentes, este médico pedia que a administração fechasse o hospício para novas remessas. Reafirmando que o hospício deveria se dedicar a receber alienados curáveis, propunha também a criação de um asilo de inválidos para aliviar o hospício, que já era ocupado por $2 / 3$ desta categoria.

As cartas dirigidas ao provedor da Santa Casa de Misericórdia por Manoel José Barbosa, e aquelas enviadas pela provedoria ao Ministério do Império até o ano de 1862, nos demonstram uma situação bem distinta daquela ressaltada por Teixeira Brandão e Juliano Moreira (Brandão, 1886; Moreira, 1903), e adotada pela historiografia. A cessão no recebimento de alienados, antes de se configurar como uma decisão arbitrária do provedor da Santa Casa, constituía-se em favor dos pedidos reiterados pelo principal médico do serviço sanitário do hospício. Da mesma forma, as reclamações feitas por este médico pautavam-se, sobretudo, na luta pela configuração de um espaço que, antes de ser um estabelecimento que

21. Maço IS 3 6, Ministério do Império - Série Saúde (1858-1863), Arquivo Nacional, AN.

22. Categorias de alienados que eram tidos como incuráveis e que sendo assim não faziam parte da clientela preferencial do Hospício Pedro II, o qual deveria ser destinado, de acordo com os seus estatutos, para os alienados passíveis de cura.

23. Nesse momento o hospício tinha capacidade para 300 pacientes.

Rev. Latinoam. Psicopat. Fund., São Paulo, v. 12, n. 2, p. 393-410, junho 2009 


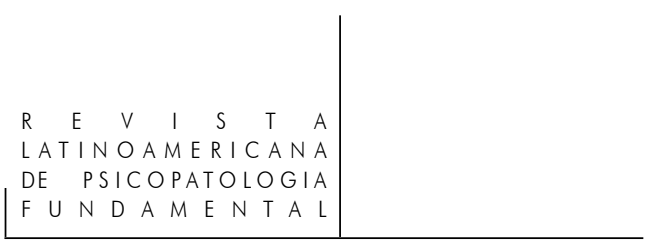

visasse à pura reclusão de alienados mentais, se pautasse na admissão de alienados passíveis de cura.

Sem entrarmos em discussões quanto às conclusões sobre o caráter curativo ou não desta instituição, ${ }^{24}$ podemos perceber que, pelo menos até a década de 1960, a provedoria do Hospício Pedro II, apesar de manter uma "feição predominante de caridade religiosa" (Venâncio, 2003), buscava, por meio do atendimento às reclamações dos facultativos responsáveis, implementar um caráter curativo ao funcionamento asilar.

Continuando a analisar as correspondências trocadas com a provedoria da Santa Casa a partir de 1862, percebemos que, apesar das decisões tomadas pela provedoria, as remessas de alienados não foram interrompidas. A capacidade do hospício, apesar de estar limitada a 300 pacientes, ficou até 1870 bem acima desta cifra. As referências aos déficits nas contas da administração do hospício e à grande quantidade de internos indigentes eram repetidas a cada pedido de internação enviado pelo Ministério do Império. Durante estas décadas, a movimentação do hospício também fora marcada por uma grande leva de pedidos de internação de militares do Exército (na sua grande maioria) e da Armada em função da Guerra do Paraguai (1864-1870) e nenhum destes pedidos era rejeitado.

Da mesma forma, continuaram a ser recorrentes os pedidos de admissão advindos das Províncias do Império, para os quais, na maior parte das vezes, a resposta era positiva. Mesmo quando a resposta era negativa, esta era acompanhada de uma justificativa sempre relacionada com a lotação do hospício. Somente na década de 70 sua lotação conseguiu ficar abaixo de 300 pacientes, contabilizando, em 1870, 297 pacientes (dos quais 209 eram indigentes e 88 pensionistas), de acordo com o relatório do médico Manoel José Barbosa. ${ }^{25}$

Ainda neste relatório Barbosa afirmava que a população do hospício não aumentava por ter sido limitada regimentalmente. E que sendo a maior parte dos internados no hospício pacientes incuráveis, o número de saídas era pequeno e, por conseguinte, o de entradas também. Tendo em vista a situação vivida desde a década de 50, o mesmo também pedia para que as províncias não remetessem mais alienados para o hospício, afirmando que estas deveriam "carregá-los" como pudessem. No mesmo sentido, reclamava a construção de um outro hospício na

24. Assunto bastante prestigiado pela historiografia e também pautado em trabalhos médicos de fins do século XIX.

25. Manoel José Barbosa. "Relatório do médico diretor do serviço sanitário do Hospício Pedro Segundo". $1^{\circ}$ de julho de 1870. Maço IS 3 7, Ministério do Império - Série Saúde (1864-1870), Arquivo Nacional, AN. 
Província do norte, atentando para as dificuldades de locomoção e para o crescimento populacional. Frisando, nessa ocasião, que um hospício não bastava para todo o Império.

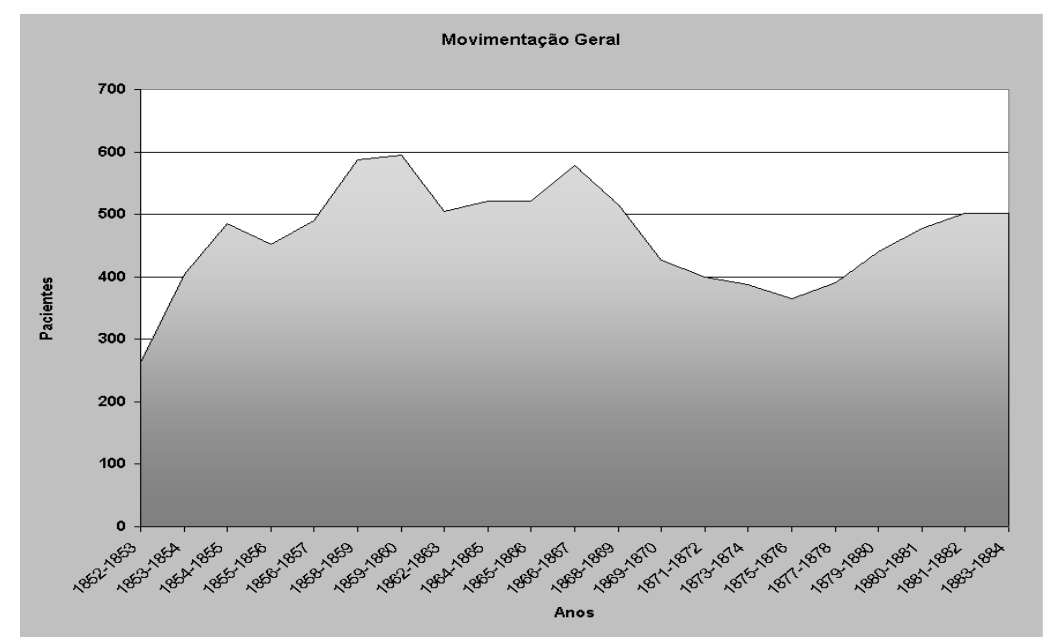

Figura 1

Movimentação Geral do Hospício Pedro II (1852-1884)

Como nas décadas anteriores, Barbosa fazia referência à necessidade de se estabelecer um asilo de inválidos no Rio de Janeiro. Dava relevo também para o fato de a cidade do Rio de Janeiro só abrigar um Asilo de Mendigos, que para ele bastava mudar de nome (pois este era "repugnante"), receber asseio, ser ampliado e logo poderiam enviar para lá 1950 ou 1960 dos alienados incuráveis e inofensivos, o que faria com que pudessem abrir as portas do Hospício Pedro II aos curáveis. Nesse mesmo documento, o médico responsável apontava para as principais doenças mentais que acometiam a população do Hospício Pedro II, sendo elas: a demência com ou sem paralisia, a mania, a monomania, a lipemania, a epilepsia, a imbecilidade e o idiotismo. Informava ainda que a maior parte dos doentes era de alienados afetados de mania, seguidos pelos que sofriam de demência simples ou sem paralisia. Concluía a sua abordagem do problema enfrentado pela presença de alienados incuráveis, relatando que havia no hospício uma mulher vinda da Santa Casa de Misericórdia que se encontrava em tratamento desde 1844. Além de outra mulher e um homem que lá estavam desde 1847, dois homens desde 1848 e um desde 1849 . Um outro grande número de pacientes tinha sido admitido nos anos de $1853,1854,1855$ e 1856 , dentre os quais a maioria era de dementes, sendo muitos afetados de paralisia. 


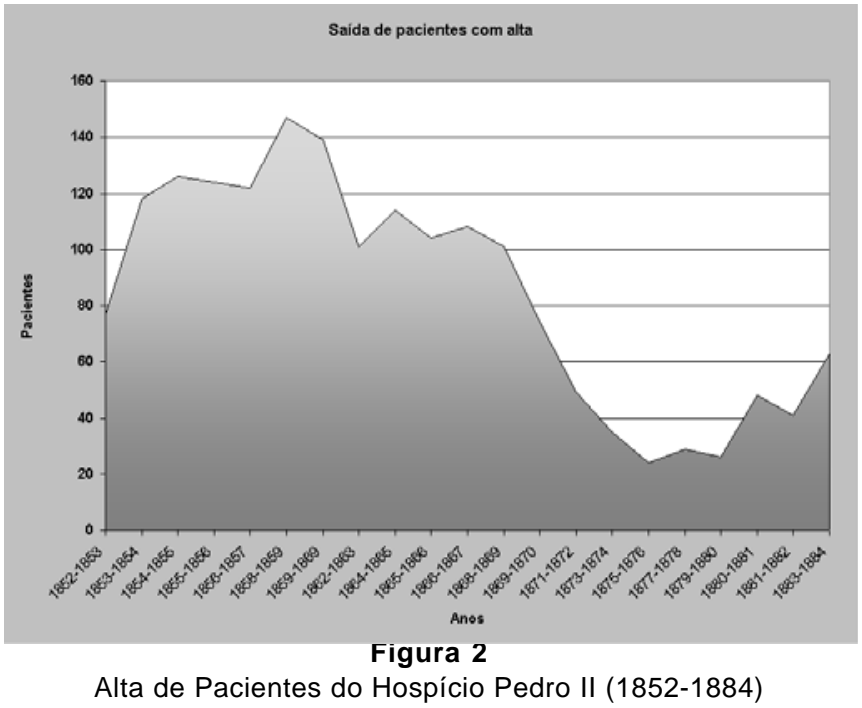

Ao contrário do que nos informa a historiografia, a limitação na entrada de pacientes desde a década de 1858, como podemos comprovar mais uma vez, fora condicionada, prioritariamente, pelas contínuas reclamações feitas pelo principal médico do hospício nestas décadas ao provedor da Santa Casa de Misericórdia. O qual chamava a atenção, sempre que tinha oportunidade, para os prejuízos gerados ao tratamento médico, pelo acúmulo de pacientes. Os pedidos feitos pelas autoridades públicas até esta década só tinham duas possibilidades de serem negados: a primeira estava relacionada com a natureza da moléstia (referindo-se aos incuráveis) e a segunda com a lotação do hospício.

No que se referia à admissão daqueles que eram recolhidos nas ruas pela polícia da Corte, a situação era diferente. Mesmo depois de 1862 era recorrente a referência a uma grande quantidade de alienados mandados para o hospício pela polícia, sem qualquer requisição à provedoria ${ }^{26} \mathrm{~A}$ entrada dos remetidos por esta autoridade era condicionada por um exame médico realizado quando da entrada do paciente. Além deste exame, o recém-chegado permanecia em observação du-

26. As remessas de pacientes a qualquer hora do dia ou da noite, assim como a verificação de que muitos haviam sofrido agressões físicas no Xadrez da polícia era uma constante nas reclamações dos médicos responsáveis pelo Hospício Pedro II, durante todo o período analisado. 
HISTÓRIA DA

PSIQUIATRIA

rante 15 dias para que fosse identificado se o mesmo sofria realmente de alienação mental e, assim sendo, se o mesmo era tido como incurável ou podia conviver com a sua família sem representar nenhum perigo de vida para si ou para os outros. Dando-se, pois, prioridade para aqueles que podiam ser curados ou representavam risco para a família ou para a sociedade, contanto que não fossem condenados ou estivessem esperando por julgamento por terem cometido algum crime. Para estes últimos, a admissão era negada tendo como base o argumento da falta de segurança para guardar alienados criminosos.

A quantidade de alienados admitidos por requisição da polícia da Corte continuou sendo predominante, contabilizando um total de $46 \%$ das requisições em 1869. ${ }^{27} \mathrm{O}$ que mais uma vez contraria os argumentos utilizados por médicos na década de 1980 de que as admissões no hospício ocorriam de forma arbitrária, por influência do provedor da Santa Casa.

Sendo assim, se após um dado momento o Asilo de Mendicidade ou mesmo a Casa de Correção da Corte e a Casa de Detenção começaram a encher de alienados, ${ }^{28}$ isto reflete o importante papel exercido pelo Hospício Pedro II em todo o Império. Como pudemos demonstrar, durante todo o período eram numerosos os pedidos de admissão advindos de todas as províncias. Da mesma forma, a reflexo do constatado na década de 1850 , não deveriam ser poucos os alienados abandonados nas ruas da Corte por vapores advindos de outras províncias com a esperança de que estes fossem recolhidos ao hospício, também nas décadas seguintes. A demanda de vagas para alienados era muito superior à capacidade do hospício, o que redundou na ida de muitos destes doentes para as demais instituições.

Desta maneira, ao analisarmos o processo de admissão de alienados no Hospício Pedro II, pudemos perceber que existia uma forte ingerência dos médicos responsáveis pelo serviço sanitário, principalmente no que se referia à prioridade na recepção de alienados. Sem entrarmos nas discussões que envolvem a crise de terapêutica moral (Dalgalarrondo, 1996), podemos verificar que existia um empenho destes médicos em dar preferência àqueles que apresentassem possibilidade de cura. Constatação que contraria a hipótese defendida pela historiogra-

27. Maço IS 3 8, Ministério do Império - Série Saúde (1871-1879), Arquivo Nacional, AN.

28. A pesquisa de doutoramento que estamos desenvolvendo coteja também a distribuição de alienados nestes outros estabelecimentos durante o Segundo Reinado e, tendo como base esta ampla pesquisa, podemos afirmar que a presença de alienados nestes estabelecimentos era muito grande.

Rev. Latinoam. Psicopat. Fund., São Paulo, v. 12, n. 2, p. 393-410, junho 2009 


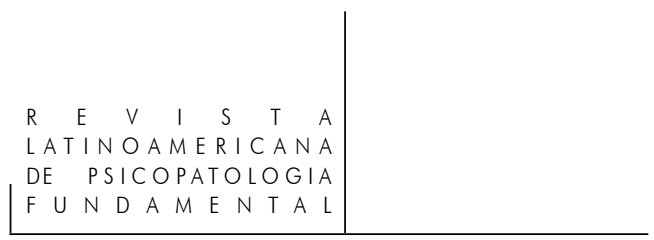

fia, até o presente momento, de que esta instituição servira somente como um mecanismo de exclusão de elementos perturbadores.

Por meio dos documentos pudemos apreender, sobretudo, que o empenho dos médicos e mesmo do provedor (que apoiava as reivindicações dos facultativos do estabelecimento) se voltava para o intuito de tratar indivíduos acometidos por distúrbios mentais. O que se contrapunha ao interesse de diversas famílias, senhores de escravos, e setores do governo, que visavam utilizar o hospício como um depósito de alienados incuráveis, tratados como indigentes.

Além disto, a percepção de que o hospício fora construído para tirar de circulação os indivíduos com conduta desviante que vagavam pelas ruas da cidade e adjacências também demonstrou ser equivocada. A enorme presença de alienados de diversas procedências, assim como a reiterada posição dos médicos do hospício de que só seriam admitidos no estabelecimento aqueles indivíduos que, tendo sido enviados pela polícia, demonstrassem ser passivos de cura ou representassem perigo para suas famílias, são uma prova desta afirmação.

\section{Fontes Primárias}

Maço IS 3 3, Ministério do Império - Série Saúde (1840-849), Arquivo Nacional, AN. Maço IS 3 4, Ministério do Império - Série Saúde (1850-1853) Arquivo Nacional, AN. Maço IS 3 5, Ministério do Império - Série Saúde (1854-1857) Arquivo Nacional, AN. Maço IS 3 6, Ministério do Império - Série Saúde (1858-1863) Arquivo Nacional, AN. Maço IS 3 7, Ministério do Império - Série Saúde (1864-1870) Arquivo Nacional, AN. Maço IS 3 8, Ministério do Império - Série Saúde (1871-1879) Arquivo Nacional, AN. Maço IS 3 9, Ministério do Império - Série Saúde (1880-1884) Arquivo Nacional, AN.

\section{Fontes Impressas}

BRANDão, J. C. T. (1886). Os alienados no Brasil. Imprensa Nacional. In: MoReIRA, J. Notícia sobre a evolução da assistência a alienados do Brasil. Arquivos Brasileiros de Psiquiatria, Neurologia e Ciências Afins, Rio de Janeiro, v. 1, n. 1, p. 52-98, 1903.

Moreira, J. Notícia sobre a evolução da assistência a alienados do Brasil. Arquivos Brasileiros de Psiquiatria, Neurologia e Ciências Afins, Rio de Janeiro, v. 1, n. 1, p. 52-98, 1903.

Rev. Latinoam. Psicopat. Fund., São Paulo, v. 12, n. 2, p. 393-410, junho 2009 
HISTÓRIA DA

PSIQUIATRIA

Silva, L. Relatório apresentado ao Provedor da Santa Casa de Misericórdia do Rio de Janeiro. Gazeta Médica da Bahia, Salvador, fevereiro e abril de 1868.

Referências

Аввотт, A. The system of professions. An essay on the division of expert labor.

Chicago and London: The University of Chicago Press, 1988.

BERCHERIE, P. Os fundamentos da clínica: história e estrutura do saber psiquiátrico. Rio de Janeiro: Jorge Zahar, 1989.

Burke, P. A escrita da história: novas perspectivas. São Paulo: Editora Unesp, 1992.

CAstel, R. A ordem psiquiátrica: a idade de ouro do alienismo. Rio de Janeiro: Graal, 1978.

Chalnoub, S. Visões da liberdade: uma história das últimas décadas da escravidão na Corte. São Paulo: Companhia das Letras, 1990.

Costa, J. F. História da psiquiatria no Brasil: um corte ideológico. Rio de Janeiro: Xenon, 1989.

Costa, N. R. Introdução. In: Tundis, S. A., CostA, N. R. (Org.). Cidadania e loucura: políticas de saúde mental no Brasil. Petrópolis, RJ: Vozes, 2000. p. 11-12.

Dalgalarrondo, P. Civilização e loucura: uma introdução à história da etnopsiquiatria. São Paulo: Lemos, 1996.

EDLER, F. C. As reformas do ensino médico e a profissionalização da medicina na Corte do Rio de Janeiro (1854-1884). 1992. 252p. Dissertação (mestrado em História), Universidade de São Paulo.

Engel, M. G. Os delírios da razão: médicos, loucos e hospícios (Rio de Janeiro, 18301930). Rio de Janeiro: Fiocruz, 2001. p. 223.

Karash, M. A vida dos escravos no Rio de Janeiro (1808-1850). São Paulo: Companhia das Letras, 1990.

MAchado, R. et al. Danação da norma: medicina social e constituição da psiquiatria no Brasil. Rio de Janeiro: Graal, 1978.

MAtтos, I. R. de. O tempo Saquarema: $a$ formação do Estado Imperial. São Paulo: Hucitec, 1990.

Oda, A. M. G. R.; Dalgalarrondo, P. História das primeiras instituições para alienados no Brasil. História, Ciências, Saúde - Manguinhos, Rio de Janeiro, v. 12, n. 3, p. 983-1010, set./dez. 2005.

Rev. Latinoam. Psicopat. Fund., São Paulo, v. 12, n. 2, p. 393-410, junho 2009 


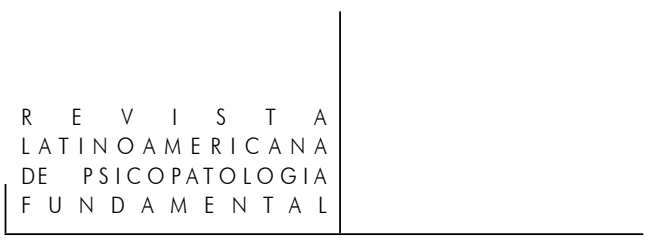

. História das primeiras instituições para alienados no Brasil. Revista

Latinoamericana de Psicopatologia Fundamental, São Paulo, v. 10, n. 2, p. 346-361, jun. 2007.

Porter, R. Uma história social da loucura. Rio de Janeiro: Jorge Zahar, 1990.

Resende, H. Política de saúde mental no Brasil: uma visão histórica. In: Tundis, S. A.; Costa, N. R. (Org.). Cidadania e loucura: políticas de saúde mental no Brasil. Petrópolis, RJ: Vozes, 2000. p. 15-73.

SAnt'Anna, M. A. De um lado, punir, de outro, reformar: projetos e impasses em torno da implantação da Casa de Correção e do Hospício de Pedro II no Rio de Janeiro. 2002. 197p. Dissertação (mestrado em História Social), Universidade Federal do Rio de Janeiro, Rio de Janeiro.

TeIXeIra, M. O. L. Deus e a ciência na terra do sol: o hospício de Pedro II e a constituição da medicina mental no Brasil. 1998. 237p. Tese (doutorado em Psiquiatria), Instituto de Psiquiatria da Universidade Federal do Rio de Janeiro.

. Os primórdios da medicina mental no Brasil e o bruxo do Cosme Velho. Cadernos IPUB, Rio de Janeiro, v. VI, n. 18, p. 84-101, 2000.

Venancio, A. T. A. Ciência psiquiátrica e política assistencial: a criação do Instituto de Psiquiatria da Universidade do Brasil. História, Ciências, Saúde - Manguinhos, Rio de Janeiro, v. 10, n. 3, p. 883-900, set.-dez. 2003.

\section{Resumos}

(Los caminos de la locura en la Corte Imperial: un embate historiográfico acerca del funcionamiento del Hospicio Pedro II de 1850 a 1889)

El tema de la alienación mental ganó prominencia en la segunda mitad del siglo XIX en Río de Janeiro, con la inauguración del Hospicio Pedro II, un espacio especial para el recogimiento y tratamiento de estos enfermos. Sin embargo, como ya ha demostrado la bibliografía sobre el tema, la trayectoria de la institución y su relación con la idea de cura y/o exclusión todavía suscita divergencias. Así siendo, en este artículo será desarrollada una discusión sobre los principales aspectos de esta cuestión, presentando el resultado del análisis de fuentes inéditas, reveladoras de nuevos aspectos de la realidad cotidiana de esa institución.

Palabras clave: Historia de medicina, alienación mental, Hospicio Pedro II, Brasil-Imperio

(Les chemins de la folie à la Cour Impériale: confrontation historiographique sur le fonctionnement de l'Hospice Pedro II de 1850 à 1889)

Le sujet de l'aliénation mentale gagne en importance au cours de la deuxième

Rev. Latinoam. Psicopat. Fund., São Paulo, v. 12, n. 2, p. 393-410, junho 2009 
moitié du siècle XIXe à Rio de Janeiro, dû à l'inauguration de l'Hospice Pedro II, un espace hospitalier spécial pour le recueillement et le traitement de ces malades. Néanmoins, comme l'a déjà démontré la bibliographie afférente au sujet, la trajectoire de cette institution et de son rapport avec l'idée de guérison et/ou d'exclusion suscite toujours des divergences. Cet article porte sur la discussion des principaux aspects de cette thématique en présentant le résultat d'une analyse de sources inédites qui révèlent de nouveaux aspects du quotidien de cette institution.

Mots clés: Histoire de la médicine, aliénation mentale, Hospice Pedro II, Brasil-Empire

(Paths of madness at the Brazilian Imperial Court: A historiographic conflict over the functioning of the Pedro II Mental Asylum, in Rio de Janeiro from 1850 to 1889)

The topic of mental alienation came into vogue during the second half of the nineteenth century in Rio de Janeiro, especially with the inauguration of the Pedro II Mental Asylum, a special hospital for taking in mental patients, referred to during this period as the "mentally alienated." However, as has been shown in the literature on the topic, the history of this particular institution and its relationship with the idea of curing and/or excluding is still the object of debate. A discussion is therefore presented here on the main aspects of this question. The article also presents the results of an analysis from unpublished sources, revealing unknown aspects of this institution.

Key words: History of medicine, mental alienation, Pedro II Mental Asylum, Brazilian Imperial Period

Citação/Citation: Gonçalves, M.S.; EdLER, F.C. Os caminhos da loucura na Corte Imperial: um embate historiográfico acerca do funcionamento do Hospício Pedro II de 1850 a 1889. Revista Latinoamericana de Psicopatologia Fundamental, São Paulo, v. 12, n. 2, p. 393-410, jun. 2009.

Editor do artigo/Editor: Prof. Dr. Paulo Dalgalarrondo e Profa. dra. Ana Maria G. Raimundo Oda.

\section{Recebido/Received: 4.5.2009 / 5.4.2009 Aceito/Accepted: 8.5.2009 / 5.8.2009}

Copyright: @ 2009 Associação Universitária de Pesquisa em Psicopatologia Fundamental/ University Association for Research in Fundamental Psychopathology. Este é um artigo de livre acesso, que permite uso irrestrito, distribuição e reprodução em qualquer meio, desde que $\mathrm{o}$ autor e a fonte sejam citados/This is an open-access article, which permits unrestricted use, distribution, and reproduction in any medium, provided the original author and source are credited.

Financiamento/Funding: Os autores declaram não ter sido financiados ou apoiados/The authors have no support or funding to report. 


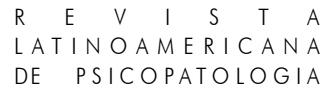

Conflito de interesses: Os autores declaram que não há conflito de interesses/The authors declare that has no conflict of interest.

\section{Monique de Siqueira Gonçalves}

Doutoranda do Programa de Pós-Graduação em História das Ciências e da Saúde da Casa de Oswaldo Cruz - COC/Fiocruz (Rio de Janeiro, RJ, Brasil)

Rua Beija-Flor, lote 20, quadra 6 - Condomínio Sítio Guararema

25745-170 Itaipava/Petrópolis, RJ, Brasil

e-mail: monique.eco@gmail.com

\section{Flávio Coelho EdLer}

Professor do Programa de Pós-Graduação em História das Ciências e da Saúde da Casa de Oswaldo Cruz - COC/Fiocruz (Rio de Janeiro, RJ, Brasil); Doutor em Saúde Coletiva, pelo Instituto de Medicina Social da Universaidade Estadual do Rio de Janeiro (Rio de Janeiro, RJ, Brasil)

Av. Brasil, 4036/400 - Manguinhos 21040-361 Rio de Janeiro, RJ, Brasil

e-mail: edler@fiocruz.br 